\title{
Decimal Place Setting And Error In AMORT Function In Texas Instruments BA-II Plus Calculator
}

Qian Huang, New York University, USA

Chee Ng, Fairleigh Dickinson University, USA

\begin{abstract}
Setting decimal places to two in Texas Instruments BA-II Plus financial calculator to be consistent with our currency denomination is insidious. It yields erroneous amortization answers that elude unsuspecting users. The only remedy to minimize the erroneous answers is to increase the decimal places to nine, the maximum permissible by the calculator.
\end{abstract}

Keywords: Amortization; Principal Reduction

\section{INTRODUCTION}

1 $\mathrm{n}$ the collegiate learning of the time value of money, also known as compounding-discounting arithmetic, hand-held financial calculators or their corresponding apps in smartphones and Microsoft Excel spreadsheet have become indispensible nowadays as they replace completely the interest-rate tables whose use has become anachronistic. Texas Instruments BA-II Plus financial calculator is arguably one of the most widely-adopted models used by instructors, students and practitioners alike. Most learning of the compoundingdiscounting arithmetic topic will culminate in the creation of the amortization table which shows the gradual decrease in periodic interest payment to service the loan, and the gradual increase in periodic equity accumulation. The BA-II Plus model has the amortization table built into its AMORT function key. Unfortunately, the AMORT function will output erroneous amortization results if the decimal-place setting of the calculator is set to either 2 or zero by unsuspecting users. This note serves to highlight such output errors, and we hope more users will be alerted of the shortcoming by setting the decimal place to 9 , the maximum allowable by the design of the calculator, in order to circumvent the output error.

\section{DECIMAL PLACE SETTING AND ERROR IN AMORT FUNCTION IN TEXAS INSTRUMENTS BA-II PLUS CALCULATOR}

The Texas Instrument BA-II Plus calculator allows its users to adjust its decimal places from 0 through 9 although its factory preset decimal places is 2 . In solving mortgage amortization problems, the choice of decimal places will produce erroneous results that are certainly non-trivial and therefore misleading to unsuspecting users, especially students and recently-adopting instructors. The severity of the errors is highest at zero decimal place, significant at 2 decimal places, and trivial when we set the decimal places to 9 which is the maximum decimal places allowed by the model. Moreover, this note is significant because the Texas Instrument BA-II Plus model is one of the two models sanctioned by the Charter Financial Analyst Institute for use in all three levels of the CFA exams worldwide.

Many students and instructors alike prefer to set the decimal places of the BA-II Plus financial calculator to 2 since the output is consistent with our currency denomination. Three globally popular introductory level finance textbooks, Brigham and Ehrhardt (2014), Berk and DeMarzo (2014), and Emery, Finnerty and Stowe (2011), all adopt the 2-decimal convention. However, such practice yields erroneous amortization results. For those who choose to be debonair, lest be accused of being punctilious, by setting the decimal place to zero so that the output yields 
only the full-dollar amount, the BA-II Plus financial calculator yields errors that are even more egregious than the answers obtained using the 2 decimal-place format. The decimal-place format can be changed by pressing the $2^{\text {nd }}$ and Format keys sequentially.

To illustrate the amortization errors, we use a numerical example of a traditional 30-year fixed-rate mortgage of principal $\$ 200,000$ at $3 \%$ yearly rate. We enter $\mathrm{N}=12 * 30=360 ; \mathrm{I} / \mathrm{Y}=3 / 12=.25 ; \mathrm{PV}=200000 ; \mathrm{CPT}$ $\mathrm{PMT}=-843.21$. Next, we enter the AMORT worksheet by pressing the $2^{\mathrm{ND}}$ and AMORT keys sequentially. We enter a value each for the P1 and P2 prompts. We then press the down arrow key $\downarrow$ for the calculator to output the remaining balance (BAL), principal reduction (PRN), and the interest paid (INT). By inputting the same P1 and P2 values in the AMORT worksheet, we are able to generate each row, which represents each month's status, of the amortization process.

Continuing with the same example above, we create an abbreviated amortization table in Microsoft Excel that presents the first three monthly payments, the last monthly payment of first year, $5^{\text {th }}$ year, $10^{\text {th }}$ year, $20^{\text {th }}$ year and the last three monthly payments of the 30-year 3\% yearly fixed-rate mortgage. We next compare the ending balance, BAL, output by the AMORT worksheet in BA-II Plus financial calculator set in three different decimal settings. We present the results in the following table.

\begin{tabular}{|l|c|c|c|c|c|c|c|c|}
\hline \multirow{2}{*}{ Mth } & Beginning & Monthly & \multirow{2}{*}{ Interest } & Principal & \multicolumn{2}{|c|}{$\begin{array}{c}\text { Ending Balance } \\
\text { Reduction }\end{array}$} & \multicolumn{3}{|c|}{ Ending Balance using BA-II Plus in: } \\
\cline { 7 - 9 } & Payment & & & Exingel & 9 Decimal & 2 Decimal & 0 Decimal \\
\hline 1 & $200,000.00$ & 843.21 & 500.00 & 343.21 & $199,656.79$ & $199,656.79$ & $199,656.79$ & 199,657 \\
\hline 2 & $199,656.79$ & 843.21 & 499.14 & 344.07 & $199,312.73$ & $199,312.73$ & $199,213.72$ & 199,313 \\
\hline 3 & $199,312.73$ & 843.21 & 498.28 & 344.93 & $198,967.80$ & $198,967.80$ & $198,967.78$ & 198,968 \\
\hline$:$ & $:$ & $:$ & $:$ & $:$ & $:$ & $:$ & $:$ & $:$ \\
\hline 12 & $196,177.16$ & 843.21 & 490.44 & 352.77 & $195,824.40$ & $195,824.40$ & $195,824.38$ & 195,826 \\
\hline$:$ & $:$ & $:$ & $:$ & $:$ & $:$ & $:$ & $:$ & $:$ \\
\hline 60 & $178,210.41$ & 843.21 & 445.53 & 397.68 & $177,812.73$ & $177,812.73$ & $177,812.59$ & 177,825 \\
\hline$:$ & $:$ & $:$ & $:$ & $:$ & $:$ & $:$ & $:$ & $:$ \\
\hline 120 & $152,501.57$ & 843.21 & 381.25 & 461.95 & $152,039.62$ & $152,039.62$ & $152,039.31$ & 152,070 \\
\hline$:$ & $:$ & $:$ & $:$ & $:$ & $:$ & $:$ & $:$ & $:$ \\
\hline 240 & $87,947.45$ & 843.21 & 219.87 & 623.34 & $87,324.11$ & $87,324.11$ & $87,323.45$ & 87,392 \\
\hline$:$ & $:$ & $:$ & $:$ & $:$ & $:$ & $:$ & $:$ & $:$ \\
\hline 358 & $2,517.03$ & 843.21 & 6.29 & 836.92 & $1,680.11$ & $1,680.11$ & $1,679.05$ & 1,794 \\
\hline 359 & $1,680.11$ & 843.21 & 4.20 & 839.01 & 841.11 & 841.11 & 840.04 & 955 \\
\hline 360 & 841.11 & 843.21 & 2.10 & 841.11 & 0.00 & 0.00 & 1.07 & 114 \\
\hline
\end{tabular}

We observe that the 9-decimal-place setting yields results that are correct when compared to those generated by the Microsoft Excel spreadsheet. However, the 2-decimal-place setting yields results from the second month through the maturity of the mortgage with discrepancy that increases with the progression of time. The 0 decimal-place setting yields results that differ from the correct answer by almost $\$ 10$ in the second month, and the error culminates at $\$ 114$ at the maturity of the 30-year mortgage. From the pattern of the errors, we conclude that the errors are cumulative over time.

We vary the fixed rate used and report the remaining balance at maturity with three different settings of the decimal places at 0,2 and 9 . 


\begin{tabular}{|c|c|c|c|c|}
\hline \multirow{2}{*}{$\begin{array}{c}\text { Interest Rate, \% } \\
\text { p.a. }\end{array}$} & \multirow{2}{*}{ Monthly Payment, \$ } & \multicolumn{3}{|c|}{ Balance at Maturity, BAL ${ }_{360}$, using Different Decimal Place Settings } \\
\hline & & Dec $=0$ & Dec $=2$ & Dec $=9$ \\
\hline 2.875 & 829.78 & 124 & 2.96 & .000000045 \\
\hline 3 & 843.21 & 114 & 1.07 & .000000021 \\
\hline 3.125 & 856.75 & 152 & 0.53 & .000000038 \\
\hline 3.25 & 870.41 & 255 & 1.77 & .000000011 \\
\hline 3.375 & 884.19 & 114 & 1.57 & .000000014 \\
\hline 3.5 & 898.09 & 65 & 0.43 & .000000028 \\
\hline 3.625 & 912.10 & 83 & 1.94 & .000000026 \\
\hline 3.75 & 926.23 & 154 & 0.73 & .000000056 \\
\hline 3.875 & 940.47 & 300 & 2.93 & .000000010 \\
\hline 4 & 954.83 & 116 & 0.63 & .000000048 \\
\hline 5 & $1,73.64$ & 290 & 2.84 & .000000238 \\
\hline 6 & $1,190.10$ & 116 & 1.04 & .000000542 \\
\hline
\end{tabular}

From the results under the Dec $=0$ and Dec $=2$ columns, we see that the magnitude of the errors is not correlated with the level of interest rates in any discernible pattern.

The remaining balance at maturity should all have been zero in value. However, if an unsuspecting user were to use zero decimal place to produce integer-only results, or two decimal places in the hope that such choice will be consistent with the denomination of our currency, then the BA-II Plus financial calculator yields non-trivial erroneous amortization answers.

The only way to avoid the erroneous answers in the AMORT worksheet in the Texas Instruments BA-II Plus financial calculator is by setting the decimal places to its maximum allowable at 9 . The factory preset of 2 decimal places, and the integer-only setting yield erroneous ending balance for the AMORT worksheet.

\section{AUTHOR INFORMATION}

Miss Qian Huang, of NYU Stern School of Business, is an accounting-economics double-major senior who aspires to study the Ph.D. degree in Accounting immediately upon graduation. E-mail: qh253@ stern.nyu.edu

Chee Ng is a professor of finance at Fairleigh Dickinson University, College at Florham, Madison, NJ. E-mail: cheeng@fdu.edu (Corresponding author)

\section{REFERENCES}

1. Berk, Jonathan, and Peter DeMarzo, 2014, Corporate finance, $3^{\text {rd }}$ edition, Pearson, Boston, MA 02116.

2. Brigham, Eugene, and Michael Ehrhardt, 2014, Financial Management: theory and practice, $14^{\text {th }}$ edition, Southwestern Cengage Learning, Mason, $\mathrm{OH} 45040$.

3. Emery, Douglas R., John D. Finnerty, and John D. Stowe, 2011, Corporate financial management, $4^{\text {th }}$ edition, Wohl Publishing, Morristown, NJ 07960. 
NOTES 